\title{
Communication Skills and Professional Practice: Does It Increase Self-Efficacy in Nurses?
}

\author{
César Leal-Costa1,2, Sonia Tirado González²,3, Antonio Jesús Ramos-Morcillo ${ }^{\text {* }}$, \\ María Ruzafa-Martínez¹, José Luis Díaz Agea ${ }^{4}$ and \\ Carlos Javier van-der Hofstadt Román ${ }^{2,5}$
}

' Nursing Department, University of Murcia (UM), Murcia, Spain, ${ }^{2}$ Instituto de Investigación Sanitaria y Biomédica de Alicante (ISABIAL), Alicante, Spain, ${ }^{3}$ Health Psychology Department, Miguel Hernandez University (UMH), Elche, Spain, ${ }^{4}$ Nursing Department, Catholic University of Murcia (UCAM), Murcia, Spain, ${ }^{5}$ Hospital Psychology Unit, University Hospital of Alicante, Alicante, Spain

The relationship between nurses and their patients is changing significantly, resulting in a patient-focused model. This work aims to contribute new knowledge about the effect of communication skills on perceived self-efficacy of nursing professionals. A cross-sectional descriptive study was conducted with a final sample consisting of 242 nurses. Different instruments that measured communication skills and the

OPEN ACCESS

Edited by:

Sara Carletto,

University of Turin, Italy

Reviewed by:

Francisco Javier Cano-García,

University of Seville, Spain

Maria Helena Barbosa,

Universidade Federal do Triângulo

Mineiro, Brazi

*Correspondence:

Antonio Jesús Ramos-Morcillo ajramos@um.es

Specialty section:

This article was submitted to Health Psychology,

a section of the journal

Frontiers in Psychology

Received: 27 January 2020

Accepted: 06 May 2020

Published: 12 June 2020

Citation:

Leal-Costa C, Tirado González S,

Ramos-Morcillo AJ,

Ruzafa-Martínez M, Díaz Agea JL and van-der Hofstadt Román CJ (2020)

Communication Skills and Professional Practice: Does It Increase Self-Efficacy in Nurses?

Front. Psychol. 11:1169.

doi: 10.3389/fpsyg.2020.01169 general and specific self-efficacy of nursing professionals were utilized. A positive and statistically significant correlation $(p<0.01)$ between the communication skills and the perceived general and specific self-efficacy was obtained. Nursing professionals who have adequate communication skills feel more confident and more competent, fostering good interpersonal relationships with their patients, and therefore, their perceived general and specific self-efficacy improved as well. Teaching communication skills is important to help nurses cope with a broad range of stressors in their daily interactions with patients, increasing their perceived self-efficacy.

Keywords: communication skills, nursing professionals, self-efficacy, patient-focused model, professional practice

\section{INTRODUCTION}

The relationship between nurses and their patients is currently undergoing significant changes, resulting in a model that is more patient-focused (Langberg et al., 2019). This new orientation stems from a holistic model, in which nurses and patients share responsibility and control, and is based on an egalitarian clinical relationship of balanced power and control (Street, 2017; Treiman et al., 2017). Among all health care professionals, nurses spend the most time with the patients; therefore, having and using appropriate communication skills with their patients is highly important and needed (Pehrson et al., 2016). According to previous studies, good communication skills of health professionals are related to successful health outcomes, such as good patient satisfaction, adherence to treatment, and improvement of the indicators of quality of care (Beach et al., 2005; Stiefel et al., 2010; Uitterhoeve et al., 2010; Barth and Lannen, 2011; Lenzi et al., 2011; Bernard et al., 2012; Rezaei and Askari, 2014; Scholl et al., 2014; Capone, 2016). The most common problems related to the communication skills of the nurses reported by the patients were the lack of information about care, inability of tending to their emotional needs, and lack of respect (Nørgaard et al., 2012). These problems thus highlight the need to investigate the communication skills of the nurses and thus their self-efficacy when performing their professional functions. 
The self-efficacy construct refers to a person's own estimation of his or her ability to perform a specific task successfully (Bandura, 1978), and the perceived self-efficacy refers to the belief that the nursing professional has the skills needed to perform the necessary actions to obtain the desired results at work. Previous studies have investigated the self-efficacy of nurses and other health professionals in training sessions related to communication skills. These programs were effective, and the professionals increased their self-efficacy post-training in diverse relational contexts (Parle et al., 1997; Ammentorp et al., 2007; Doyle et al., 2011; Nørgaard et al., 2012). Nevertheless, there is an information gap about how the communication skills (provide and obtain information, respect, empathy, etc.) of the nurses relate to their self-efficacy when performing nursing interventions.

Thus, this work aims to contribute new knowledge about the effect of communication skills (informative communication, empathy, respect, and social skill) on perceived self-efficacy (general and specific with relational skills) of nursing professionals.

In this study, the following hypothesis was tested:

H1: Communication skills are positively associated with general and specific self-efficacy of nursing professionals.

\section{METHOD}

\section{Design}

A cross-sectional correlational ex post facto study conducted with a nursing professionals' sample from Alicante, Spain.

\section{Participants}

The sample was selected through non-probability convenience sampling. As inclusion criteria, all the participants had to (1) work in hospital or primary care setting, (2) be a registered nurse, (3) be actively working with a minimum experience of 1 year, and (4) provide direct care to patients.

The sample size needed was calculated, and the results showed that a sample size of 242 nurses achieved $100 \%$ power to detect a difference of -0.50 between the null hypothesis correlation of 0.00 and the alternative hypothesis correlation of 0.50 using a two-sided hypothesis test with a significance level of 0.05 (Algina and Olejnik, 2003).

\section{Instruments}

The participants completed a self-report questionnaire that included the following:

The participant's sociodemographic and professional information, age, sex, marital status, other graduate and postgraduate degrees, length of time worked, type of center (public, public with private management, or private), and place of work (hospital, specialty center, primary care, or other), was evaluated.

The Communication Skills Scale (CSS; Leal-Costa et al., 2016, Leal-Costa et al., 2019) was utilized to evaluate the communication skills of the nurses. This scale is composed of 18 items, with a Likert-type response scale, and was scored with a 6point frequency scale which indicated how often they performed the item. Two items were worded inversely (items 18 and 20). It included four dimensions: (a) Informative Communication, consisting of six items $(5,8,9,14,17$, and 18), which reflect the manner in which the health professionals obtain and provide information on the clinical relationship they establish with patients; (b) Empathy, composed of five items (2, 4, 6, 11, and 12 ), which reflect the capacity of the health professionals to comprehend the feelings of patients and make their empathy evident in the relationship, as well as the behavioral dimension, the empathic attitude, composed of active listening and empathic response; (c) Respect, with three items (21,3, and 15), which evaluate the respect that is shown by the health professionals in the clinical relationship established with patients; and d) Social Skills, with four items $(17,10,13$, and 16) that reflect the ability of the health professionals to be assertive or to exhibit socially skillful behaviors in the clinical relationship established with patients. The Cronbach's alpha $(\alpha)$ was 0.77 for empathy, 0.78 for informative communication, 0.74 for respect, and 0.65 for social skills. Evidences of content validity were obtained with a qualitative evaluation phase of the items with a group of experts and construct validity which related the communication skills with burnout (Leal-Costa et al., 2016).

\section{General Self-Efficacy Scale}

The Spanish adaptation of Sanjuán Suárez et al. (2000) scale was used, which consists of 10 items with a 4-point Likert response scale. It measures the level of general self-efficacy, understood as a global construct that refers to the stable belief of people about their ability to adequately handle a wide range of stressors from everyday life. The scale had a Cronbach's $\alpha$ of 0.87 and 0.88 correlation halves.

\section{Specific Self-Efficacy Scale}

The Specific Self-Efficacy Scale for communication in difficult situations (Doyle et al., 2011) is composed of two scales: the Extent of Difficulty Scale developed by Arranz et al. (2005) and the Confidence Scale developed by Parle et al. (1997). The difficulty scale measures the ability of nurses to handle problems during their interaction with patients, family, and the health care team. The "confidence" scale measures the confidence of the professionals themselves for handling situations regarding patients. The internal consistency for the self-efficacy scales was excellent (confidence $=0.88$, difficulty $=0.90)$ (Doyle et al., 2011).

\section{Implementation}

The data were collected from June to September 2016. The selfadministered questionnaire with the tools described, informed consent, and project information sheet were created with the Google Forms tool. Collaboration requests were distributed to all the nurses by the Nursing Council of the Province of Alicante. The online questionnaires were sent via e-mail on two separate occasions to obtain the sample size needed and to ensure its representativeness. All the response data from the nurses were collected in a Google spreadsheet for analysis. 


\section{Data Analysis}

Data analysis was performed using the SPSS statistical package version 22.0 (IBM Inc. 2013, NYC) and AMOS version 18.

Descriptive statistics were calculated as frequencies for categorical variables, whereas means and standard deviations were computed for continuous variables. For the analysis of the correlation between the communication skills and self-efficacy, Pearson's bivariate correlations were used.

The variables showed adequate normality for the maximum likelihood estimation (MLE) method, i.e., skewness $>2-3$ and kurtosis >7-10 (Marôco, 2014). To test the model hypothesis, a path analysis technique was performed. The significance of the regression coefficients was evaluated after the estimation of the parameters with the maximum likelihood estimation method. The significance of effects was assessed with bootstrap resampling (Marôco, 2014). The effects with $p \leq 0.05$ were considered significant. The fit of the model was evaluated using the $\chi^{2} / d f<5$; the root mean square error of approximation (RMSEA) values $\leq 0.08$, and the comparative fit index (CFI), goodness of fit index (GFI), and Tucker-Lewis (TLI) index values $\geq 0.90$ indicate a good fit (Kline, 2011).

\section{Ethical Considerations}

All the participants gave their consent to participate in the study, which was approved by the Ethics Committee of the University Miguel Hernández, Spain (reference number DPS-CVR-00111). The principal bioethical aspects were settled by ensuring voluntary and informed participation and the confidentiality of the data and information of the study participants.

\section{RESULTS}

The sample was composed by 242 nurses, of whom 207 (85.5\%) were women and 35 (14.5\%) were men. The participants' average age was 39.60 years [standard deviation $(\mathrm{SD})=10.51$ ], and the average time working as a nurse was 16.62 years $(\mathrm{SD}=21.09)$. Regarding their civil status, 53 (21.9\%) were single, 167 (69\%) were married or cohabiting, 15 (6.2\%) were separated, and seven (2.9\%) were widowers. The distribution according to type of management of the centers and place of work showed that 182 $(75.2 \%)$ worked in public centers, $31(12.8 \%)$ in privately run public centers, and $29(12 \%)$ in private centers. Furthermore, $153(63.2 \%)$ worked in hospitals, 41 (16.9\%) in primary care, four $(1.7 \%)$ in specialty centers, and $44(18.2 \%)$ in other areas, such as nursing homes, municipalities, and non-hospital emergency centers. When asked if they had another bachelor's degree (i.e., other than nursing), 38 participants $(15.7 \%)$ said yes; these included psychology, anthropology, physiotherapy, nutrition and dietetics, and social work. As to whether they had a postgraduate degree, 106 (43.8\%) answered yes; these were in nursing-related disciplines.

Regarding the reliability analysis of the scales, the internal consistency $(\alpha)$ of the CSS was 0.92 for the complete scale, 0.79 for empathy, 0.80 for informative communication, 0.77 for respect, and 0.70 for social skill. The $\alpha$ of the General and Specific Self-Efficacy Scale was 0.87 and 0.93 , respectively.
The results showed that the nursing professionals had good communication skills and perceived self-efficacy (general and specific with nursing communication) (Table 1).

As for the relationship between communication skills and self-efficacy, a positive and statistically significant correlation was observed $(p<0.01)$ (Table 2). Correlation coefficients were obtained that oscillated between 0.265 and 0.606 , with the strength of the relationship being moderate.

The proposed model (Figure 1) attempted to test the hypothesis of the relationship between communication skills and general and specific self-efficacy of nursing professionals. Figure 1 shows the model with the standardized regression coefficients and $R^{2}$ values.

The model fit showed a moderate adjusted model $\chi^{2} / d f=3.22$, RMSEA $=0.09(90 \% \mathrm{CI}=0.063-0.131)$, CFI $=0.97$, GFI $=0.96$, TLI $=0.94$. All the trajectories were statistically significant $(p<0.05)$.

\section{DISCUSSION}

Nursing professionals can experience difficulties when communicating with patients, patients' family, and other colleagues in the clinical context (Arranz et al., 2005). However, having good communication skills can be important to help nurses cope with a broad range of stressors in their interactions with patients, family, and other colleagues, increasing their perceived self-efficacy. This study aimed to analyze the relationship between communication skills and general and specific self-efficacy of nursing professionals.

TABLE 1 | Descriptive statistics of the Communication Skills Scale and the General and Specific Self-Efficacy.

\begin{tabular}{lcccc}
\hline Instruments & $\boldsymbol{M}$ & SD & Skewness & Kurtosis \\
\hline Communication skills scale & 89.26 & 9.89 & -0.14 & -0.79 \\
$\quad$ Empathy & 24.77 & 3.36 & -0.37 & -0.51 \\
$\quad$ Informative communication & 30.91 & 3.44 & -0.27 & -0.87 \\
Respect & 15.73 & 2.02 & -0.59 & -0.70 \\
Social Skills & 17.85 & 3.13 & -0.29 & 0.73 \\
General self-Efficacy scale & 32.36 & 4.25 & -0.40 & 0.50 \\
Specific self-Efficacy scale difficulty & 86.26 & 11.90 & -0.97 & 1.39 \\
Specific self-Efficacy scale confidence & 64.12 & 12.63 & -0.77 & 0.94 \\
\hline
\end{tabular}

TABLE 2 | Bivariate correlations between the total and dimensions of the CSS and the General and Specific Self-Efficacy.

\begin{tabular}{llll}
\hline CSS & GSS & SSSD & SSSC \\
\hline Total & $0.493^{\star \star}$ & $0.400^{\star \star}$ & $0.578^{\star \star}$ \\
Empathy & $0.464^{\star \star}$ & $0.384^{\star \star}$ & $0.606^{\star \star}$ \\
Informative communication & $0.433^{\star \star}$ & $0.329^{\star \star}$ & $0.478^{\star \star}$ \\
Respect & $0.334^{\star \star}$ & $0.265^{\star \star}$ & $0.367^{\star \star}$ \\
Social Skill & $0.367^{\star \star}$ & $0.320^{\star \star}$ & $0.413^{\star \star}$
\end{tabular}

${ }^{* *} p<0.01$. CSS, Communication Skills Scale; GSS, General Self-Efficacy Scale; SSSD, Specific Self-Efficacy Scale Difficulty; SSSC, Specific Self-Efficacy Scale Confidence. 


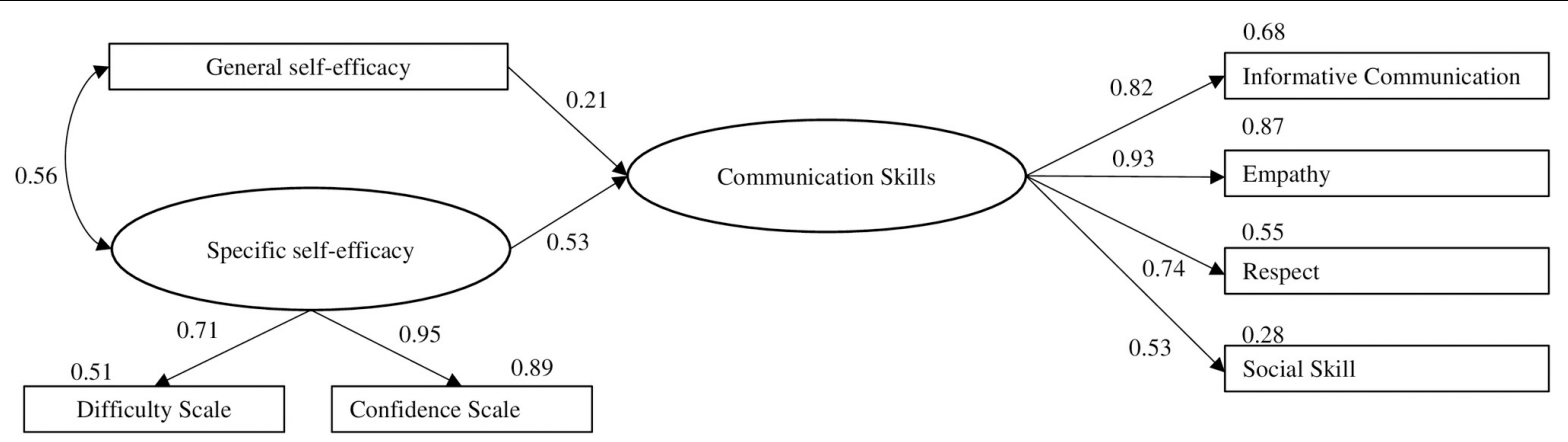

FIGURE 1 | Model of the effect of communication skills and general and specific self-efficacy of nursing professionals with standardized parameter estimates.

The results showed that the nursing professionals had high scores in the dimensions of communication skills and selfefficacy (general and specific with nursing communication). These results are consistent with another study conducted with a larger sample of health professionals (doctors, nursing professionals, and auxiliary nursing) (Leal-Costa et al., 2015, 2019). In the multivariate analysis, we found the expected effect of the communication skills on general and specific self-efficacy, confirming the proposed hypothesis.

The results obtained also provided a model which indicated that if nurses have good communication skills, these can contribute to making them feel more secure and competent and can thus enhance their interpersonal relationships with the patients. This in turn helps nurses to cope with a broad range of stressors, thus increasing their self-efficacy (general and specific to nursing communication). These results were consistent with other similar studies (Parle et al., 1997; Arranz et al., 2005; Ammentorp et al., 2007; Doyle et al., 2011; Nørgaard et al., 2012; Park et al., 2015; Chan and Sy, 2016).

Thus, nurses who have good communication skills could feel more secure and competent in their interactions with patients, indicating that teaching communication skills is important to help nurses cope with a broad range of stressors and to increase their perceived self-efficacy. The adjusted model used in this study demonstrated the relationship between communication skills and general and specific self-efficacy.

Another study (Park et al., 2015) found a positive correlation between communication skills and perceived self-efficacy of nurses of an emergency department. However, our work establishes a model of the effect of the communication skills on general and specific self-efficacy, with standardized regression coefficients of 0.21 and 0.53 , respectively.

Therefore, increasing the communication skills of the nurses can positively affect the interventions performed in the different care services, as the nurses feel able to perform the actions needed to obtain the results sought in their work.

\section{Limitations}

The study had several limitations. On the one hand, the study was carried out in a single province, with nursing professionals working in primary and specialized care. A study which includes more provinces would enrich the results and could reinforce or weaken the results obtained. Also, the sample was selected using a non-probabilistic convenience sampling method, and the study was cross-sectional. Thus, the generalization of the results should be made with caution, with studies that use more complex designs needed in order to show how the communication skills of the nurses affect their perceived general self-efficacy. To show the existence of a causal relationship, experimental designs should be implemented with random assignment of the subjects to the study conditions.

\section{CONCLUSION}

Despite the above limitations, we can establish the following conclusion: our findings support the hypothesis that communication skills can positively affect perceived self-efficacy (general and specific with relational skills).

\section{DATA AVAILABILITY STATEMENT}

The datasets analyzed in this article are not publicly available. Requests to access the datasets should be directed to cleal@um.es.

\section{ETHICS STATEMENT}

All the participants gave their consent to participate in the study, which was approved by the Ethics Committee of the University Miguel Hernández, Spain (reference number DPS-CVR-00111). The principal bioethical aspects were settled by ensuring voluntary and informed participation and the confidentiality of the data and information of the study participants.

\section{AUTHOR CONTRIBUTIONS}

CL-C, JD, AR-M, ST, MR-M, and CH contributed to the conceptualization, formal analysis, and writing, reviewing, and editing. JD, ST, and CL-C contributed to data curation. JD, AR$\mathrm{M}, \mathrm{MR}-\mathrm{M}$, and CL-C contributed to the investigation. JD, CH, 
MR-M, ST, and CL-C contributed to the methodology. ST and CL-C and contributed to project administration. $\mathrm{CH}$ and CL$\mathrm{C}$ contributed to the resources. AR-M and CL-C acquired the

\section{REFERENCES}

Algina, J., and Olejnik, S. (2003). Sample size tables for correlation analysis with applications in partial correlation and multiple regression analysis. Multiv. Behav. Res. 38, 309-323. doi: 10.1207/S15327906MBR3803_02

Ammentorp, J., Sabroe, S., Kofoed, P.-E., and Mainz, J. (2007). The effect of training in communication skills on medical doctors' and nurses' self-efficacy. A randomized controlled trial. Patient Educ. Counsel. 66, 270-277. doi: 10.1016/ j.pec.2006.12.012

Arranz, P., Ulla, S. M., Ramos, J. L., Del Rincón, C., and López-Fando, T. (2005). Evaluation of a counseling training program for nursing staff. Patient Educ. Counsel. 56, 233-239. doi: 10.1016/j.pec.2004.02.017

Bandura, A. (1978). Self-efficacy: toward a unifying theory of behavioral change. Adv. Behav. Res. Therapy 1, 139-161. doi: 10.1016/0146-6402(78)9 0002-4

Barth, J., and Lannen, P. (2011). Efficacy of communication skills training courses in oncology: a systematic review and meta-analysis. Ann. Oncol. 22, 1030-1040. doi: 10.1093/annonc/mdq441

Beach, M. C., Sugarman, J., Johnson, R. L., Arbelaez, J. J., Duggan, P. S., and Cooper, L. A. (2005). Do patients treated with dignity report higher satisfaction, adherence, and receipt of preventive care? Ann. Fam. Med. 3, 331-338. doi: 10.1370/afm.328

Bernard, M., de Roten, Y., Despland, J.-N., and Stiefel, F. (2012). Oncology clinicians' defenses and adherence to communication skills training with simulated patients: an exploratory study. J. Cancer Educ. 27, 399-403. doi: 10.1007/s13187-012-0366-8

Capone, V. (2016). Patient communication self-efficacy, self-reported illness symptoms, physician communication style and mental health and illness in hospital outpatients. J. Health Psychol. 21, 1271-1282. doi: 10.1177/ 1359105314551622

Chan, J. C.-Y., and Sy, P. Y. (2016). The relationships among personality, intercultural communication, and cultural self-efficacy in nursing students. J. Nurs. Res. JNR 24, 286-290. doi: 10.1097/JNR.0000000000000157

Doyle, D., Copeland, H. L., Bush, D., Stein, L., and Thompson, S. (2011). A course for nurses to handle difficult communication situations. A randomized controlled trial of impact on self-efficacy and performance. Patient Educ. Counsel. 82, 100-109. doi: 10.1016/j.pec.2010.02.013

Kline, R. B. (2011). Principles and Practice of Structural Equation Modeling. New York, NY: Guilford Publications.

Langberg, E. M., Dyhr, L., and Davidsen, A. S. (2019). Development of the concept of patient-centredness - A systematic review. Patient Educ. Counsel. 102, 1228-1236. doi: 10.1016/j.pec.2019.02.023

Leal-Costa, C., Díaz-Agea, J. L., Tirado-González, S., Rodríguez-Marín, J., and Van-der Hofstadt, C. J. (2015). Las habilidades de comunicación como factor preventivo del síndrome de Burnout en los profesionales de la salud. An. Sistema Sanitario Navarra 38, 213-223. doi: 10.4321/s113766272015000200005

Leal-Costa, C., Tirado González, S., Ramos-Morcillo, A. J., Díaz Agea, J. L., RuzafaMartínez, M., Van-der Hofstadt, et al. (2019). Validation of the Communication Skills Scale in nursing professionals. An. Sistema Sanitario Navarra 42, 291-301. doi: 10.23938/ASSN.0745

Leal-Costa, C., Tirado-González, S., Rodríguez-Marín, J., and vander-HofstadtRomán, C. J. (2016). Psychometric properties of the health professionals communication skills scale (HP-CSS). Int. J. Clin. Health Psychol. 16, 76-86. doi: 10.1016/j.ijchp.2015.04.001

Lenzi, R., Baile, W. F., Costantini, A., Grassi, L., and Parker, P. A. (2011). Communication training in oncology: results of intensive communication software. CH and CL-C contributed to supervision. CL-C, ST, and MR-M contributed to validation. CL-C, ST, and $\mathrm{CH}$ contributed to writing the original draft.

workshops for Italian oncologists. Eur. J. Cancer Care 20, 196-203. doi: 10.1111/ j.1365-2354.2010.01189.x

Marôco, J. (2014). Analysis of Structural Equations: TheoreticalFundamentals, Software \& Applications, 2 Edn. Pêro Pinheiro: ReportNumber.

Nørgaard, B., Ammentorp, J., Kyvik, K. O., and Kofoed, P.-E. (2012). Communication skills training increases self-efficacy of health care professionals. J. Continuing Educ. Health Profess. 32, 90-97. doi: 10.1002/chp. 21131

Park, M. S., Jeoung, Y., Lee, H. K., and Sok, S. R. (2015). Relationships among communication competence, self-efficacy, and job satisfaction in Korean nurses working in the emergency medical center setting. J. Nurs. Res. JNR 23, 101-108. doi: 10.1097/JNR.0000000000000059

Parle, M., Maguire, P., and Heaven, C. (1997). The development of a training model to improve health professionals' skills, self-efficacy and outcome expectancies when communicating with cancer patients. Soc. Sci. Med. 44, 231-240. doi: 10.1016/s0277-9536(96)00148-7

Pehrson, C., Banerjee, S. C., Manna, R., Shen, M. J., Hammonds, S., Coyle, N., et al. (2016). Responding empathically to patients: development, implementation, and evaluation of a communication skills training module for oncology nurses. Patient Educ. Counsel. 99, 610-616. doi: 10.1016/j.pec.2015.11.021

Rezaei, F., and Askari, H. A. (2014). Checking the relationship between physicians' communication skills and outpatients' satisfaction in the clinics of Isfahan AlZahra(S) Hospital in 2011. J. Educ. Health Promot. 3:105. doi: 10.4103/22779531.139697

Sanjuán Suárez, P., García Pérez, A. M., and Moreno Bermúdez, J. (2000). Escala de autoeficacia general: Datos psicométricos de la adaptación para población española. Psicothema 12, 509-513.

Scholl, I., Zill, J. M., Härter, M., and Dirmaier, J. (2014). An integrative model of patient-centeredness-A systematic review and concept analysis. PLoS One 9:e107828. doi: 10.1371/journal.pone.0107828

Stiefel, F., Barth, J., Bensing, J., Fallowfield, L., Jost, L., Razavi, D., et al. (2010). Communication skills training in oncology: a position paper based on a consensus meeting among European experts in 2009. Ann. Oncol. 21, 204-207. doi: 10.1093/annonc/mdp564

Street, R. L. (2017). The many «Disguises» of patient-centered communication: problems of conceptualization and measurement. Patient Educ. Counsel. 100, 2131-2134. doi: 10.1016/j.pec.2017.05.008

Treiman, K., McCormack, L., Olmsted, M., Roach, N., Reeve, B. B., Martens, C. E., et al. (2017). Engaging patient advocates and other stakeholders to design measures of patient-centered communication in cancer care. Patient 10 , 93-103. doi: 10.1007/s40271-016-0188-6

Uitterhoeve, R. J., Bensing, J. M., Grol, R. P., Demulder, P. H. M., and van Achterberg, T. (2010). The effect of communication skills training on patient outcomes in cancer care: a systematic review of the literature. Eur. J. Cancer Care 19, 442-457. doi: 10.1111/j.1365-2354.2009.01082.x

Conflict of Interest: The authors declare that the research was conducted in the absence of any commercial or financial relationships that could be construed as a potential conflict of interest.

Copyright (C) 2020 Leal-Costa, Tirado González, Ramos-Morcillo, Ruzafa-Martínez, Díaz Agea and van-der Hofstadt Román. This is an open-access article distributed under the terms of the Creative Commons Attribution License (CC BY). The use, distribution or reproduction in other forums is permitted, provided the original author(s) and the copyright owner(s) are credited and that the original publication in this journal is cited, in accordance with accepted academic practice. No use, distribution or reproduction is permitted which does not comply with these terms. 